\title{
Research and Measurement on Promoting Quality of Graduate Project for Undergraduate
}

\author{
Chongfang $\mathrm{Fu}$ \\ School of Information Engineering \\ Nanchang Hangkong University \\ Nanchang, China \\ fcfnc2006@126.com \\ Min Liu \\ School of Information Engineering \\ Nanchang Hangkong University \\ Nanchang, China \\ darai@126.com
}

\author{
Zhongming Li \\ School of Information Engineering \\ Nanchang Hangkong University \\ Nanchang, China \\ zhongmli@gmail.com \\ Fuya Wei \\ School of Information Engineering \\ Nanchang Hangkong University \\ Nanchang, China \\ Wfy196@163.com
}

\begin{abstract}
This paper aims at solving current problems exist among undergraduates finishing their final project. In order to help realize an overall improvement and strengthen the management of teaching quality, the team carry out a series of eminently achievable measures to insure the quality of graduation projects based on teaching teams at grass-roots level after thorough analysis from professional view. This would also lay a solid foundation for improving the quality of talent cultivation.
\end{abstract}

Keywords-teaching team; graduate project; quality; management

\section{INTRODUCTION}

Design of graduate project should be consider as an important practical teaching link in undergraduates' specialty cultivation program. As the last comprehensive link in college teaching process, it can be a summary of learning, research and practice achievement for undergraduates, meanwhile, the project always plays a vital education basis to evaluate efforts made by both students and teachers. The link is set to test the ability of undergraduates to use their knowledge to analyze real problems comprehensively and independently before taking measures to solve them. It's time to start attach importance to combining theory to practice which cannot be divorcing from rigorous attitude and cooperation. All the efforts would help to improve undergraduates' capability of composite analysis, scientific research, foreign publications reading, computer and expressing. However, it seems to be a common phenomenon among universities in China, in varying degrees, quality of graduate project declined. Copy and cheating exist everywhere.

Owing to its significant effect on the teaching quality and educational quality at college, a discussion around how to guarantee the quality of graduate design has been put on the agenda officially in most universities. Professional teaching teams are best qualified to speak on this question, for they are the basic unit of implement this teaching program. The team proposed several suggestions for improving quality of graduate design based on years of experience directing graduate project.

\section{MAIN FACTORS INFLUENCING THE QUALITY OF GRADUATION DESIGN}

\section{A. Management System[1]}

Because of multiple nodes and long running time, formal management is the basic guarantee of the quality of undergraduate graduation design. Our school has printed an instruction manually for undergraduate graduation design and formulated the regulations and administrative measures to standardize the manipulation during the teaching process. However, poor operability and inadequate implementation of those regulations, which makes these measurements only exist in the form without expected effect. Graduation design has a high requirement both of comprehensive and concrete guidance, together with flexible teaching methods from teachers; meanwhile, it needs a spirit of innovation and great independence for students. Nevertheless, as we mentioned above, poor operability induces that it can't play its role to supervise both teachers and students. Eventually, some important procedure cannot obtain enough attention which woud influences the quality of graduate design directly.

\section{B. Faculty Adviser}

Regardless of the students' employment demand when teachers choose topic for them, which brings about the difficulty in stimulating the enthusiasm of students. Considerable part of subjects belonging to pure theory subjects leads to a result that student have no idea where to start with. Also, strong randomness, wide range, difficult to organize and deviating from the direction of own major makes the cultivation in students' comprehensive quality meaningless.

Guidance not in place and decreasing guidance level are also reasons for decreasing quality of graduate design [2]. With a massive college enrollment expansion, relatively stable 
numbers of teachers can't catch up with the demand of rapidly increasing student's quantity. Guidance available now are too busy with their own scientific researches, graduate students and heavy teaching assignments, which would reduce their input in guiding graduate project more or less. Youngsters, meanwhile, cannot guide a project on their own because of lacking of experience in both production and enterprises. The laissez-faire attitude leads to unsatisfying results.

\section{Graduates}

Students behave badly in analyzing and solving the problems in practice. Recently, high education enrollment scale increasing dramatically lowers the quality of undergraduate students. Many problems are exposed, for instance, poor capacity for literature search and reading, bad hands-on skills, inadequate ability to handle the problem independently in hardware design, judgment ability to make plans, poor writing and all sorts of cheating to copy problems [3].

The contradiction between finding jobs and graduate design and worse employment condition resulted from the college expansion plan and employment system. Too much energy is devoted to finding jobs, further education, and practice and so on. In addition, Department of Student Affairs gives the pass to graduates' job-finding so that students pay little attention to graduate design consequently, without a doubt.

Students pay little attention to graduate design because its quality makes no difference to their graduation. So they temporize in periodic examination and copy in paper.

\section{CREATE A PEOPLE-ORIENTED MANAGEMENT ATMOSPHERE FOR GRADUATE DESIGNING PROCESS}

There are few things you can do to change the macroenvironment as a professional teaching team, but there are details that can be different which will also lead to huge leaps in improving the quality of graduate project. Here follows the concrete measures:

\section{A. Expand the Faculty Advisor Team to Ensure Adequate Project Resources.}

Communication Engineering has always been a "hot major" among our university, only few students are given students the chance to attend the major even if it is their first choice of major each year. However, the number of teachers didn't increase in proportion with the expansion in quantity of students. In order to avoid to pushing them to do something without interest like other major, measures such as exploring new opportunities to outstanding scholars to be their guidance have been taken. Firstly, contact with companies provides internships, striving for guidance outside school. Secondly, keep touch with some executive staff in college and other professionals related to work on some project which can figure out real problems. And lastly, contact with electronic basis department of college to win their support.

Thanks to all above, our graduate project are abundant and creative without breaking rules of college even when we are suffering from shortage of staffs.
Encourage students to choose their own project, mainly for students who take part in innovative contests or other activities. Teachers can guide them to do further researches on their original foundation. For instance, there was precedents that enterprises bought patents from undergraduates which provides opportunities for starting their own business.

\section{B. Standardize Operation Details to Eliminate Loopholes in Management}

Bring forward the preparation for design of graduate project. Though it should be done during eighth semester, we prepare during seventh semester. Firstly, faculty advisers declare, check and modify the subjects during September and October; secondly, announce the subjects and students make choices, and then faculty advisers meet with students, assign tasks and look for information; finally, graduates should hand in proposal before the eighth semester. These are all for students to arrange their time.

To avoid "false" phenomenon, we should strengthen the subject audit meaning that faculty advisers are divided into groups according to researching direction to check the subjects. They should mark the subjects according to not only the content of the paper, but also the requirement of subjects and the form of the achievement. Faculty advisers need to amend the unqualified subjects and then they need another check. Only the qualified subjects will be chosen by students. Meanwhile, we make sure that the quantity of subjects is more than the 1.2 times the number of students, thus, to ensure enough choices for each students.

More strict process management means that faculty advisers should fill in a guidance record and note some details like the time, problems they solved, tasks, schedule and where they meet. Moreover, faculty adviser and students need to sign on the record, which is kept by teacher, and then it is supposed to hand in twice every week. Thus both teachers and students are supervised. Specialized site for design of graduate project and equipment should be offered and it needs a sign with both faculty adviser and student to get equipment. It should ensure each section of work responsibility to each person. All faculty advisers should take turns to tour the office to have a better understanding about the situation of their designs.

Strengthen the mid-term examination. There are about 4 times check during the whole design process whose time should be announced in advance. Under the supervision of a group of experts, as the first part, thesis proposal is aimed at examining the quality of the proposal and the situation about translation for literature and then guiding the project charter, project return and registration of graduate design outside the school of faculty advisers during early March. The second one, approximately in the end of March, is to arrange faculty advisers of each examination group to check the achievement to learn about the schedule. Next, in the middle of April, cross inspection is to give a chance for teachers of defense group to know about the achievement of each student in order to have an impression because, at this time, inspection group consists of the teachers of defense group. There will be advisement for each inspection to students about the design, and especially for those jogging, they will receive a written opinions going with a 
notification. If they are notified every time, their design will be ended automatically. Finally, after manufacture inspection, those whose production can't reach the standard have another chance to be checked. They can't enter the defense segment until their manufacture passes the examination. The whole faculty advisers may absolutely feel tired with such inspection; however, it can help many negative graduates.

Treat the grade of graduate design cautiously and objectively. The mark of graduate design accounts considerably in total mark and also plays a significant role in selecting outstanding graduates. After graduates having achieved their thesis, the group of teaching will appoint a faculty adviser to review the paper. In brief, the grade of graduate design consists of five parts:

Manufacture $30 \%$ (according to 3 inspections); defense $20 \%$ (marked by defense group); paper $40 \%$ (30\% according to faculty adviser, $10 \%$ according to review teacher); daily performance $10 \%$ (marked by touring group).

Asking for leave is a significant part through the graduate design. Matters like finding jobs, reexamine adjustment for further education, civil service examination, linked with employment closely will inevitably lead to frequently asking for leave. Correspond method is that students must hand in a written document demonstrating the reasons to corresponding teachers and then the faculty adviser agrees only it doesn't influence the design schedule. Graduates can ask for leave successfully after get the agreement of department in order that professional department, teaching team and faculty advisers can control the schedule of graduate design.

\section{ACKNOWLEDGMENT}

The essay is one of phased objectives in 2011 belonging to a teaching team of school.

\section{REFERENCES}

[1] Zhuli, Yuan Rongxin. Management practice and reflection on quality of final projects (thesis) for undergraduates [J]. Exploration and Practice 2013: 161-162.

[2] Yang Zhuojuan, Yang Xiaodong. Analysis on the rationality and necessity of existence of final project (thesis) for undergraduates [J]. Heilongjiang Researches on Higher Education, 2011, (9) :161-162.

[3] Qu Xia, Zou Ling. Exploration for management process on final project (thesis) for undergraduates [J]. China Electric Power Education, 2013 (16) : 143-144 